\title{
Energy Balance Simulation of a Wheat Canopy USING THE RZ-SHAW (RZWQM-SHAW) MODEL
}

\author{
Q. Yu, G. N. Flerchinger, S. Xu, J. Kozak, L. Ma, L. Ahuja
}

\begin{abstract}
RZ-SHAW is a new hybrid model coupling the Root Zone Water Quality Model (RZWQM) and the Simultaneous Heat and Water (SHAW) model to extend RZWQM applications to conditions of frozen soil and crop residue cover. RZ-SHAW offers the comprehensive land management options of RZWQM with the additional capability to simulate diurnal changes in energy balance needed for simulating the near-surface microclimate and leaf temperature. The objective of this study was to evaluate RZ-SHAW for simulations of radiation balance and sensible and latent heat fluxes over plant canopies. Canopy energy balance data were collected at various growing stages of winter wheat in the North China Plain $\left(36^{\circ} 57^{\prime} \mathrm{N}, 116^{\circ}\right.$ $6^{\prime} E, 28 \mathrm{~m}$ above sea level). RZ-SHAW and SHAW simulations using hourly meteorological data were compared with measured net radiation, latent heat flux, sensible heat flux, and soil heat flux. RZ-SHAW provided similar goodness-of-prediction statistics as the original SHAW model for all the energy balance components when using observed plant growth input data. The root mean square error (RMSE) for simulated net radiation, latent heat, sensible heat, and soil heat fluxes was 29.7, 30.7, 29.9, and $25.9 \mathrm{~W} \mathrm{~m}^{-2}$ for SHAW and 30.6, 32.9, 34.2, and $30.6 \mathrm{~W} \mathrm{~m}^{-2}$ for RZ-SHAW, respectively. Nash-Sutcliffe $R^{2}$ ranged from 0.67 for sensible heat flux to 0.98 for net radiation. Subsequently, an analysis was performed using the plant growth component of RZ-SHAW instead of inputting LAI and plant height. The model simulation results agreed with measured plant height, yield, and LAI very well. As a result, RMSE for the energy balance components were very similar to the original RZ-SHAW simulation, and latent, sensible, and soil heat fluxes were actually simulated slightly better. RMSE for simulated net radiation, latent heat, sensible heat, and soil heat fluxes was 31.5, 30.4, 30.2, and $27.6 \mathrm{~W} \mathrm{~m}^{-2}$, respectively. Overall, the results demonstrated a successful coupling of RZWQM and SHAW in terms of canopy energy balance simulation, which has important implications for prediction of crop growth, crop water stress, and irrigation scheduling.
\end{abstract}

Keywords. Crop growth model, RZWQM, SHAW, Surface energy fluxes.

$\mathrm{T}$ he surface energy balance is one of the most essential components in process-based ecological models, as it is one of the fundamental elements influencing soil water and heat transfer. In turn, it defines nutrient cycling and crop growth. The Root Zone Water Quality Model (RZWQM) is a comprehensive agricultural system model for predicting soil physical and chemical processes and crop growth, in which soil water, heat transfer, evapotranspiration, and biomass accumulation are essential components of the model (Ahuja et al., 2000a). The model was designed to simulate carbon-nitrogen cycles, as well as water and fertilizer management. The Green-Ampt equation is used for water infiltration during rainfall irrigation events, and the Richards equation is used for water redistribution be-

Submitted for review in March 2006 as manuscript number SW 6399; approved for publication by the Soil \& Water Division of ASABE in August 2007.

The authors are Qiang Yu, Professor, Institute of Geographica Sciences and Natural Resources Research, Chinese Academy of Sciences, Beijing, China; Gerald N. Flerchinger, ASABE Member Engineer, Research Hydraulic Engineer, USDA-ARS Northwest Watershed Research Center, Boise, Idaho; Shouhua Xu, Research Associate, Institute of Geographical Sciences and Natural Resources Research, Chinese Academy of Sciences, Beijing, China; and Joseph Kozak, Soil Scientist, Liwang Ma, Research Soil Scientist, and Laj Ahuja, Supervisory Soil Scientist, USDA-ARS Agricultural Systems Research Unit, Fort Collins, Colorado. Corresponding author: Gerald N. Flerchinger, USDA-ARS, 800 Park Blvd., Suite 105, Boise, ID 83712; phone: 208-422-0716; fax: 208-334-1502; e-mail: gflerchi@nwrc.ars.usda.gov. tween events (Ahuja et al., 2000b). Potential evapotranspiration simulation is based on the Shuttleworth-Wallace equations (Farahani et al., 1996). Soil heat flux is simulated using the Fourier heat transfer equation (Ahuja et al., 2000b). A generic plant growth model was developed to simulate plant growth (e.g., root growth, leaf area index, plant height, grain yield, and biomass; Hanson, 2000) for a variety of crops. RZWQM was extensively evaluated for assessing the impact of agricultural management on soil and water quality and crop production (Ma et al., 2000; Ahuja and Ma, 2002a, 2002b).

Similarly, the Simultaneous Heat and Water (SHAW) model simulates heat, water, and solute transfer within a onedimensional profile that includes the effects of plant cover, dead plant residue, and snow. SHAW employs the Richards equation for soil water movement and solves the heat flux equation for soil temperature. Although SHAW includes a plant canopy structure with a detailed plant transpiration and canopy profile, it does not have a plant growth component like RZWQM. A major advantage of the SHAW model is its simulation of snow dynamics and over-winter conditions (Flerchinger and Saxton, 1989a; Flerchinger and Pierson, 1991). Because of its layered canopy structure, SHAW can simulate temperature in the plant canopy, surface residue, and soil surface. The SHAW model has been critically validated against experimental data (Flerchinger and Saxton, 1989b; Hymer et al., 2000; Kennedy and Sharratt, 1998; Link et al., 2004; Flerchinger et al., 2002; among others). 
Recently, a hybrid model coupling RZWQM and SHAW (RZ-SHAW) was developed to improve the energy balance, soil surface temperature, and over-winter frozen soil simulation in RZWQM (Aiken et al., 1997; Flerchinger et al., 2000). Flerchinger et al. (2000) tested RZ-SHAW for over-winter conditions with flat and standing crop residues for snow depth, ice contents, soil water content, and soil temperature. The RZ-SHAW simulation results were similar to the original SHAW model, thereby extending the application of RZWQM to conditions of frozen and residue covered soil. However, RZ-SHAW has not been evaluated for crop canopy energy balance.

The objectives of this study were to: (1) evaluate RZSHAW and SHAW for surface energy balance by comparing their simulated energy components with experimental field results at various growing stages using hourly meteorological data and measured plant growth data; and (2) evaluate RZSHAW-simulated energy balance components with the plant growth component enabled in order to assess the interaction of the plant growth routines with the modified energy balance routines.

\section{MATerials AND MethodS \\ MODEL DEVELOPMENT}

RZWQM includes physical processes, soil chemical and nutrient processes, pesticide processes, plant growth, and agricultural management (Ahuja et al., 2000a; Ma et al., 2000). Soil water movement in RZWQM is treated in two discrete phases: infiltration and redistribution within the soil profile. The Green-Ampt equation is used to simulate infiltration, and the one-dimensional Richards equation is used to simulate water redistribution. The modified Brooks-Corey equations are used to represent relationships between water content and hydraulic conductivity of soils as functions of matric potential. RZWQM calculates potential evapotranspiration (ET) by an extended Shuttleworth-Wallace equation that includes surface residue effects; actual ET is based on the soil's ability to supply water to the soil surface to meet potential ET, in which soil water movement is computed by the Richards equation (Ahuja et al., 2000a).

RZWQM uses a generic plant growth module (Hanson, 2000) capable of predicting the relative responses of several important crops to environmental variance and management manipulation. The plant routine simulates growth, development, phenology, plant nitrogen demand, and yield of a crop growing on a uniform area of land in response to changes in management, soil water, and nitrogen.

The SHAW model was originally developed by Flerchinger and Saxton (1989a) and modified by Flerchinger and Pierson (1991) to include transpiring plants and a plant canopy consisting of a vertical, one-dimensional profile extending from the vegetation canopy to a specified depth within the soil. A layered system is established through the plant canopy, snow, residue, and soil, and each layer is represented by an individual node. The interrelated energy and water fluxes at the surface boundary are computed in the SHAW model from weather observations of air temperature, wind speed, relative humidity, and solar radiation. The model can be run with either hourly or daily weather observations. Detailed descriptions of energy and mass transfer calculations within the canopy, snow, and residue layers are given by Flerchinger and
Pierson (1991), Flerchinger et al. (1994, 1996a, 1996b, 1998), and Flerchinger and Saxton (1989a).

Computed surface energy balance fluxes include absorbed solar radiation, long-wave radiation exchange, and turbulent transfer of heat and vapor. Net radiation is determined by computing solar and long-wave radiation exchange between canopy layers, residue layers, and the soil surface and considers direct and upward and downward diffuse transmitted, reflected, and absorbed by each layer. Sensible and latent heat fluxes of the surface energy balance are computed from temperature and vapor gradients between the canopy surface and the atmosphere using a bulk aerodynamic approach with stability corrections.

Provisions for a plant canopy in the SHAW model made by Flerchinger and Pierson (1991) include heat and water transfer through the soil-plant-atmosphere continuum. The plant canopy may be divided into as many as ten layers. Heat and water fluxes within the canopy include solar and longwave radiation, turbulent transfer of heat and water vapor, and transpiration from plant leaves. Transpiration from plants is linked mechanistically to soil water by flow through the roots and leaves along a gradient in water potential through the soil-plant-atmosphere continuum. Within the plant, water flow is controlled mainly by changes in stomatal resistance, which is computed as a function of leaf water potential. Turbulent heat and vapor transfer within the canopy are determined by computing transfer between layers of the canopy and considering the source terms for heat and transpiration from the canopy leaves for each layer within the canopy. The leaf energy balance is computed iteratively with heat and water vapor transfer equations and transpiration within the canopy. Water vapor and sensible heat transfer within each canopy layer are calculated by iteration for convergence of (1) leaf temperature in the leaf energy balance equation and (2) water vapor and air temperature in within-canopy transfer equations.

The RZ-SHAW hybrid model uses the soil water balance and chemical transport routines from the RZWQM model; the soil heat transfer component is taken from the SHAW model. Surface energy balance and canopy structure from the SHAW model are used in RZ-SHAW. The generic crop growth module in RZWQM supplies leaf area index, plant height, and root distribution. Unlike RZWQM, RZ-SHAW calculates actual evapotranspiration (AET) from hourly, rather than daily, surface energy balance and vapor transfer (Flerchinger et al., 2000; Ahuja et al., 2000b). Unlike the SHAW model, the surface energy balance and soil heat flux are solved separately from the soil water redistribution. Therefore, soil evaporation within the SHAW module of RZSHAW is limited to soil water movement to the upper boundary computed by the Richards equation. More details on the development of RZ-SHAW are available from Flerchinger et al. (2000). An energy balance closure is presumed in both SHAW and RZ-SHAW in a vertical dimension.

\section{Field STUdY}

A field study was performed to compare RZ-SHAW and SHAW simulation results for surface energy balance components under varying crop growth stages with experimental observations. The experimental study was conducted in a $300 \times 300 \mathrm{~m}$ wheat plot in 2003 at the Yucheng Comprehensive Experiment Station $\left(36^{\circ} 50^{\prime} \mathrm{N}, 116^{\circ} 34^{\prime} \mathrm{E}, 28 \mathrm{~m}\right.$ above sea level) of the Chinese Academy of Sciences, located on the 
Table 1. Physical and chemical properties of soil at the Yucheng study site.

\begin{tabular}{|c|c|c|c|c|c|c|c|c|c|}
\hline \multirow[b]{2}{*}{$\begin{array}{c}\text { Layer } \\
(\mathrm{cm})\end{array}$} & \multirow[b]{2}{*}{ Texture } & \multicolumn{3}{|c|}{ Composition } & \multirow{2}{*}{$\begin{array}{c}\text { Organic } \\
\text { Matter } \\
(\%)\end{array}$} & \multirow{2}{*}{$\begin{array}{c}\text { Total } \\
\text { Nitrogen } \\
(\%)\end{array}$} & \multirow[b]{2}{*}{$\mathrm{pH}$} & \multirow{2}{*}{$\begin{array}{c}\text { Water } \\
\text { Capacitance } \\
\left(\mathrm{m}^{3} \mathrm{~m}^{-3}\right)\end{array}$} & \multirow{2}{*}{$\begin{array}{c}\text { Bulk } \\
\text { Density } \\
\left(\mathrm{g} \mathrm{cm}^{-3}\right)\end{array}$} \\
\hline & & $\begin{array}{c}\text { Sand } \\
(\%)\end{array}$ & $\begin{array}{l}\text { Silt } \\
(\%)\end{array}$ & $\begin{array}{c}\text { Clay } \\
(\%)\end{array}$ & & & & & \\
\hline $0-20$ & Silt loam & 12.85 & 65.10 & 22.05 & 0.86 & 0.052 & 8.26 & 0.35 & 1.27 \\
\hline $21-60$ & Silt loam & 11.31 & 67.01 & 21.69 & 0.45 & 0.030 & 8.14 & 0.35 & 1.36 \\
\hline $61-100$ & Sandy loam & 28.30 & 58.02 & 13.68 & 0.37 & 0.024 & 7.87 & 0.31 & 1.40 \\
\hline
\end{tabular}

North China Plain. The soil profile was $1 \mathrm{~m}$ in depth and composed of a bi-layer silty loam and sandy loam; detailed physical and chemical properties of the test soil are summarized in table 1 . The site was subjected to a temperate monsoon climate with rainfall concentrated in summer and rarely occurring through the wheat growth period during winter and spring. Irrigation water was occasionally applied as needed by flood irrigation to reduce water stress in the growing crop. The winter wheat variety used in this study was Zhixuan No. 1; wheat was planted on 13 October 2002 in south-north rows, emerged on 20 October 2002, began to senesce on 6 May 2003, and was harvested on 10 June 2003. During the growing season, the leaf area index (LAI) was measured every $5 \mathrm{~d}$ by numbering plants, harvesting ten randomly within a $1 \mathrm{~m}^{2}$ plot, and measuring their leaf area with a leaf area meter (LI-3100, Li-Cor, Inc., Lincoln, Neb.). Data are summarized in table 2.

Measurements of meteorological variables, the components of the surface energy balance, and soil water content and temperature were made in the middle of the $300 \times 300 \mathrm{~m}$ plot. Wind direction and speed, humidity, temperature, soil heat flux, and air pressure were measured with a potentiometer (Windvane, model W200P, Vector Instruments, Rhyl, U.K.), an anemometer (A100R, Vector Instruments, Rhyl, U.K.), a humidity probe (HMP45C, Vaisala, Helsinki, Finland), a self-calibrating heat flux sensor (HFP01SC, Hukseflux, Delft, The Netherlands), and a barometer (CS105, Helsinki, Vaisala, Finland), respectively. Total and net radiation data were collected using a pyranometer (CM11, Kipp and Zonen, Delft, The Netherlands) and a four-component net radiometer (CNR-1, Kipp and Zonen, Delft, The Netherlands), respectively. The instruments above were located at a height of $2.8 \mathrm{~m}$ above ground.

Table 2. Measured GLAI and plant height of winter wheat for the $\mathbf{2 0 0 3}$ growing season.

\begin{tabular}{ccc}
\hline $\begin{array}{c}\text { Date } \\
(2003)\end{array}$ & $\begin{array}{c}\text { GLAI } \\
\left(\mathrm{m}^{2} \mathrm{~m}^{-2}\right)\end{array}$ & $\begin{array}{c}\text { Plant Height } \\
(\mathrm{cm})\end{array}$ \\
\hline 19 March & 0.18 & 6.0 \\
24 March & 0.31 & 8.2 \\
29 March & 0.61 & 11.6 \\
3 April & 0.84 & 13.3 \\
8 April & 1.65 & 22.5 \\
13 April & 2.05 & 24.4 \\
18 April & 2.55 & 38.3 \\
23 April & 3.47 & 43.1 \\
28 April & 3.88 & 47.8 \\
3 May & 3.89 & 62.1 \\
8 May & 3.61 & 71.5 \\
13 May & 2.77 & 71.5 \\
18 May & 2.34 & 71.5 \\
23 May & 2.13 & 71.5 \\
28 May & 1.77 & 71.5 \\
2 June & 0.86 & 71.5 \\
\hline
\end{tabular}

Latent and sensible heat fluxes over the wheat canopy, and soil heat flux were measured by the eddy covariance method during the wheat growth period. A three-dimensional sonic anemometer (model CSAT3, Campbell Scientific, Inc., Logan Utah) and an open-path infrared gas analyzer (IRGA; model LI-7500, Li-Cor, Inc., Lincoln, Neb.) mounted at a height of $2.8 \mathrm{~m}$ measured the three components of the wind velocity vector, sonic temperature, and the concentrations of water vapor and $\mathrm{CO}_{2}$. Soil heat flux was measured with a heat flux sensor (HFP01, Hukseflux, Delft, The Netherlands) installed $0.05 \mathrm{~m}$ below the soil surface. Hourly soil heat flux measured at $5 \mathrm{~cm}$ was adjusted to the surface by correcting for heat storage above $5 \mathrm{~cm}$ based on the soil bulk density, soil water content, and the average temperature change during the hour. Soil temperature and water content were measured by four soil heat flux sensors (TCAV, Campbell Scientific, Inc., Logan, Utah) installed at depths of $0.00,0.10,0.20$, and $0.50 \mathrm{~m}$ and eight water content reflectometers (CS616_L, Campbell Scientific, Inc., Logan, Utah) installed horizontally at the depths of $0.00,0.05,0.10,0.15,0.20,0.40,0.60$, and $1.0 \mathrm{~m}$ below grade.

The closure of the surface energy balance equation was analyzed to test the quality of the data (Lee and Yu, 2004). The total sensible and latent heat fluxes $\left(\mathrm{H}_{\mathrm{s}}+\lambda \mathrm{E}\right)$ were $73 \%$ of available energy $\left(R_{n}-G\right)$ during the entire growth season (fig. 1). This is similar to other energy balance closure tests (Wilson et al., 2002). Before comparing measured values with simulated fluxes, the turbulent fluxes were adjusted to force energy balance closure while maintaining the Bowen ratio (Twine et al., 2000). This was problematic when the Bowen ratio approached -1.0 . Therefore, whenever the magnitude of $\mathrm{H}_{\mathrm{s}}+\lambda \mathrm{E}$ was greater than the error in the energy

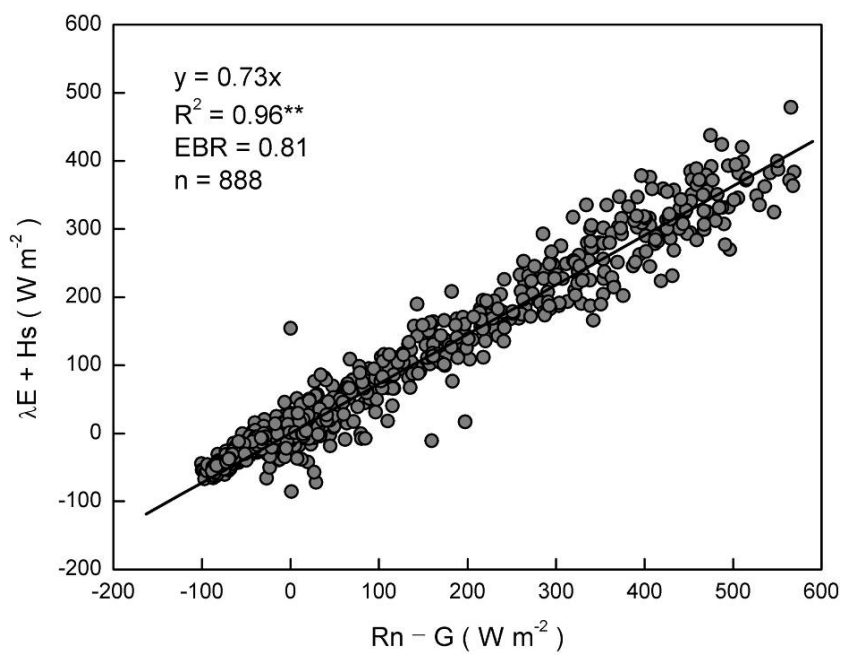

Figure 1. Energy balance closure for 21 March to 19 May in Yucheng station $\left({ }^{* *}\right.$ indicates regression is significant at 0.01 level; EBR denotes energy balance ratio, i.e., the ratio of the sum of the turbulent fluxes to the total available energy). 
balance, the error was divided equally between the two components.

\section{Model Simulation}

RZ-SHAW and SHAW simulations were performed for the growing season between 21 March and 19 May (days 80 and 139) using hourly meteorological data. Both model simulations were driven using field conditions, and the plant growth data summarized in table 2 . The models were initialized with measured soil water content on 21 March and updated with observed LAI and crop height throughout the simulations. This analysis was performed to verify that the hybrid model's simulation of energy balance compared well with that of the SHAW model. Additionally, the surface energy components simulated from both models were compared to the experimental results from the field study. The models were not calibrated for these simulations.

Subsequently, RZ-SHAW was used to simulate the entire crop season with the crop growth routine enabled; this allowed the simulated plant growth and soil moisture balance from the start of planting to be used. Model calibration was performed with respect to the plant growth input parameters and is discussed below.

\section{Results AND Discussion SHAW AND RZ-SHAW ANALYSIS}

In this study, we compared canopy energy balance simulations for the RZ-SHAW and SHAW models at various growth stages. The net radiation, sensible heat, latent heat, and soil heat fluxes at each growth stage of wheat were simulated with SHAW and RZ-SHAW and were compared to measured values in the spring of 2003. Measured plant height, LAI, and root distribution were input approximately every 10 days into both RZ-SHAW and SHAW for the period 21 March through 19 May 2003 (days 80-139). The SHAW model is capable of

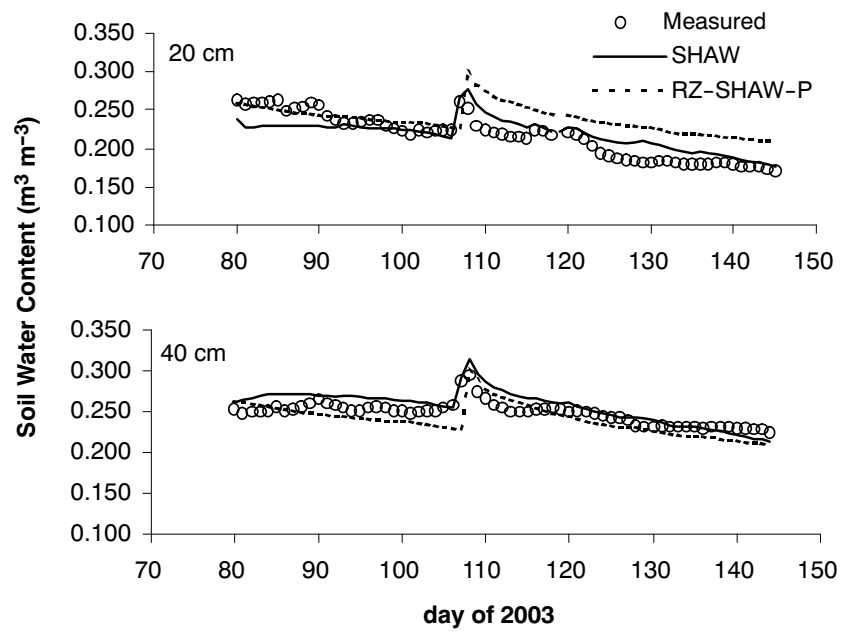

Figure 2. Measured and simulated soil water content for SHAW and RZSHAW-P simulations during the spring growing season 2003.

interpolating between LAI observations. Because RZSHAW cannot run continuously while updating LAI, it was necessary to start and stop the model each time LAI was updated. This occasionally resulted in slight discrepancies in input LAI between the two models. RZ-SHAW was initialized at these intervals with measured soil water contents as well.

Simulated soil water content for the 20 and $40 \mathrm{~cm}$ depths from the SHAW model are presented in figure 2. Except for an initial drainage of the $20 \mathrm{~cm}$ layer, the SHAW model tracked soil water content quite well; root mean square error (RMSE) of the SHAW simulation compared to measured values was $0.017 \mathrm{~m}^{3} \mathrm{~m}^{-3}$ for the $20 \mathrm{~cm}$ layer and $0.012 \mathrm{~m}^{3} \mathrm{~m}^{-3}$ for the $40 \mathrm{~cm}$ layer. Because SHAW tracked measured soil water content closely and RZ-SHAW was updated approximately every 10 days with measured soil water content, differences between the two simulations due to differences in water content are negligible.

\begin{tabular}{|c|c|c|c|c|c|c|c|c|}
\hline \multirow[b]{2}{*}{ Period } & & \multirow{2}{*}{$\begin{array}{l}\text { Average } \\
\left(\mathrm{W} \mathrm{m}^{-2}\right)\end{array}$} & \multicolumn{3}{|c|}{$\operatorname{MBE}\left(\mathrm{W} \mathrm{m}^{-2}\right)$} & \multicolumn{3}{|c|}{$\operatorname{RMSE}\left(\mathrm{W} \mathrm{m}^{-2}\right)$} \\
\hline & & & SHAW & RZ-SHAW & RZ-SHAW-P & SHAW & RZ-SHAW & RZ-SHAW-P \\
\hline \multirow{4}{*}{$\begin{array}{l}21 \text { March to } 19 \text { May } \\
\text { (days 80-139) }\end{array}$} & $\mathrm{R}_{\mathrm{n}}$ & 96.6 & 7.0 & 8.6 & 9.1 & 29.7 & 30.6 & 31.5 \\
\hline & $\lambda \mathrm{E}$ & 80.5 & -4.7 & -11.7 & -11.4 & 30.7 & 32.9 & 30.4 \\
\hline & $\mathrm{H}_{\mathrm{s}}$ & 7.7 & 10.9 & 19.8 & 15.3 & 29.9 & 34.2 & 30.2 \\
\hline & $\mathrm{G}$ & 8.6 & 0.8 & 0.5 & 5.3 & 25.9 & 30.6 & 27.6 \\
\hline \multirow{4}{*}{$\begin{array}{l}21 \text { March to } 1 \text { April } \\
\text { (days 80-91) }\end{array}$} & $\mathrm{R}_{\mathrm{n}}$ & 66.9 & 11.1 & 18.9 & 5.7 & 28.8 & 31.6 & 27.7 \\
\hline & $\lambda \mathrm{E}$ & 42.7 & 7.4 & 3.3 & -1.7 & 23.9 & 25.4 & 22.4 \\
\hline & $\mathrm{H}_{\mathrm{s}}$ & 11.3 & 6.1 & 17.4 & 8.8 & 24.5 & 31.3 & 21.9 \\
\hline & $\mathrm{G}$ & 13.5 & -2.4 & -1.7 & -1.4 & 31.6 & 42.2 & 30.6 \\
\hline \multirow{4}{*}{$\begin{array}{l}2 \text { to } 21 \text { April } \\
\text { (days } 92-111 \text { ) }\end{array}$} & $\mathrm{R}_{\mathrm{n}}$ & 84.0 & 9.8 & 6.7 & 5.9 & 36.4 & 36.6 & 35.6 \\
\hline & $\lambda \mathrm{E}$ & 67.6 & 3.1 & -7.9 & -4.3 & 32.5 & 32.0 & 30.3 \\
\hline & $\mathrm{H}_{\mathrm{s}}$ & 8.9 & 7.0 & 16.6 & 11.5 & 27.6 & 32.7 & 26.2 \\
\hline & $\mathrm{G}$ & 7.5 & 0.3 & -2.1 & -1.2 & 30.0 & 33.6 & 28.0 \\
\hline \multirow{4}{*}{$\begin{array}{l}22 \text { April to } 5 \text { May } \\
\text { (days 112-125) }\end{array}$} & $\mathrm{R}_{\mathrm{n}}$ & 112.0 & 7.7 & 10.1 & 14.5 & 28.0 & 30.3 & 33.2 \\
\hline & $\lambda \mathrm{E}$ & 102.3 & -15.4 & -17.9 & -19.4 & 32.2 & 33.2 & 32.0 \\
\hline & $\mathrm{H}_{\mathrm{s}}$ & 0.3 & 19.8 & 27.8 & 23.6 & 37.6 & 40.4 & 38.2 \\
\hline & $\mathrm{G}$ & 9.4 & 3.3 & 0.8 & 10.4 & 19.6 & 20.5 & 21.7 \\
\hline \multirow{4}{*}{$\begin{array}{c}6 \text { to } 19 \text { May } \\
\text { (days 126-139) }\end{array}$} & $\mathrm{R}_{\mathrm{n}}$ & 123.7 & -1.0 & 1.0 & 11.1 & 20.5 & 18.6 & 26.7 \\
\hline & $\lambda \mathrm{E}$ & 108.4 & -15.2 & -23.5 & -21.2 & 31.8 & 38.8 & 34.4 \\
\hline & $\mathrm{H}_{\mathrm{S}}$ & 10.3 & 11.4 & 18.8 & 17.7 & 28.5 & 31.5 & 32.4 \\
\hline & $\mathrm{G}$ & 5.0 & 2.7 & 5.6 & 14.6 & 19.3 & 21.7 & 29.5 \\
\hline
\end{tabular}



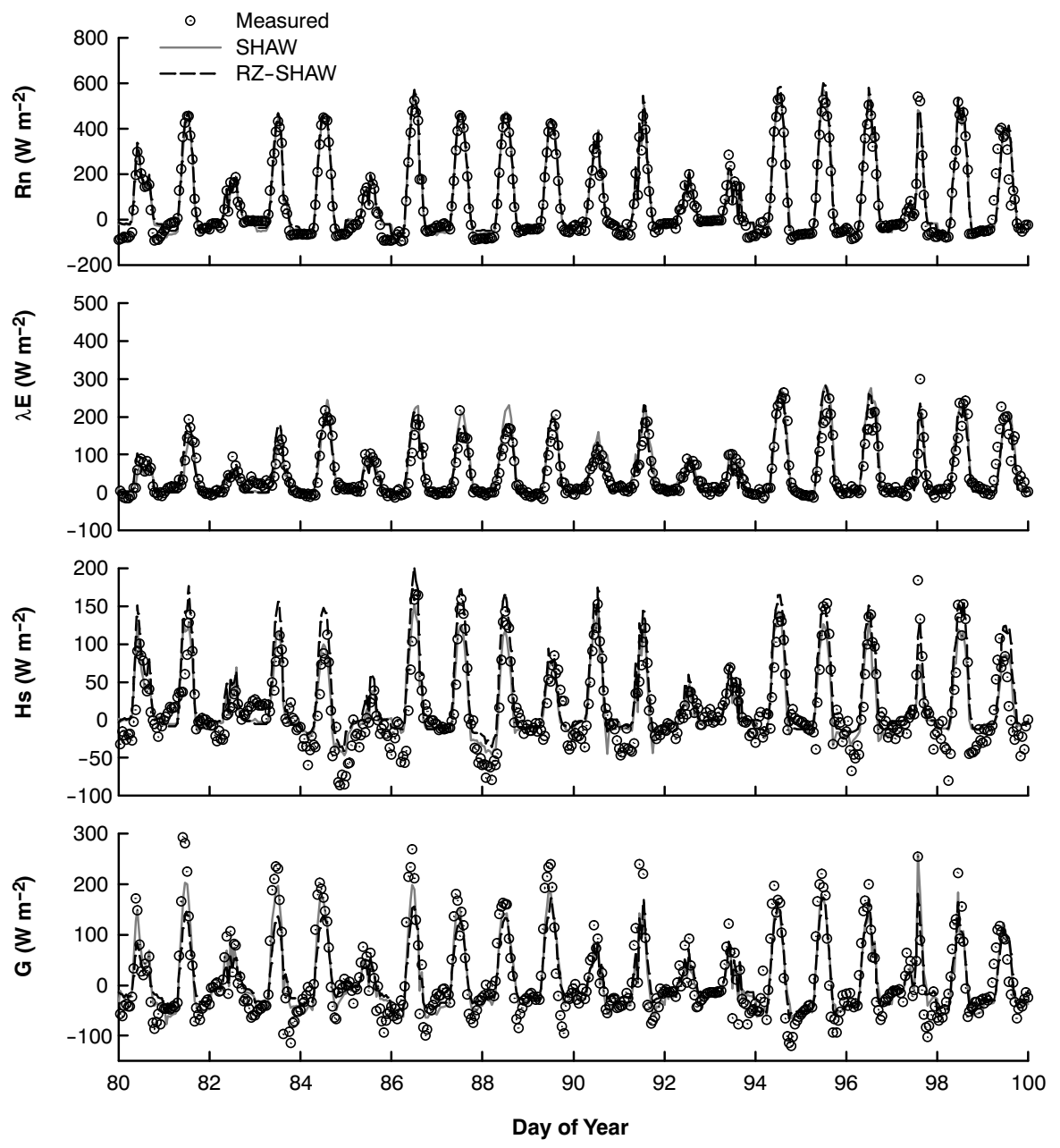

Figure 3. Measured and simulated diurnal variations of net radiation $\left(\mathbf{R}_{n}\right)$ and latent $(\lambda E)$, sensible $\left(H_{s}\right)$, and soil heat fluxes $(G)$ using SHAW and $R Z$ SHAW for 21 March to 9 April 2003 (days 80-99).

Statistics comparing the mean bias error (MBE) and RMSE of the model simulations to hourly observations are presented in table 3. Model simulations for SHAW and RZSHAW show similar statistical comparisons with measured values (table 3), suggesting a successful implementation of the SHAW routines into RZWQM. For the entire simulation (days 80-139), RMSE for the four energy balance components ranged from 25.9 to $30.7 \mathrm{~W} \mathrm{~m}^{-2}$ for SHAW and from 30.6 to $34.2 \mathrm{~W} \mathrm{~m}^{-2}$ for RZ-SHAW, suggesting that all components were simulated with similar absolute accuracy. However, because the variation and average of $\mathrm{H}_{\mathrm{s}}$ and $\mathrm{G}$ were much smaller than $R_{n}$ or $\lambda E$, the relative errors for $H_{s}$ and $G$ were somewhat higher. Nash-Sutcliffe $\mathrm{R}^{2}$ values (Nash and Sutcliffe, 1970) for the SHAW simulation were 0.98 for $R_{n}, 0.90$ for $\lambda \mathrm{E}, 0.67$ for $\mathrm{H}_{\mathrm{s}}$, and 0.85 for $\mathrm{G}$ (not shown in table 3). Values for RZ-SHAW were similar. Simulations tended to overpredict $\mathrm{H}_{\mathrm{s}}$, particularly for the later growth stages when LAI was higher (table 3); this may be due to the tendency of SHAW routines to overpredict leaf canopy temperature (Xiao et al., 2006a).

Figure 3 shows energy balance component simulations of winter wheat during the greening stage (days 80-91) and stem extension prophase (days 92-99). In the greening stage, air and soil temperature began to rise, the winter wheat broke dormancy, and development started. LAI and plant height increased from 0.18 to $0.84 \mathrm{~m}^{2} \mathrm{~m}^{-2}$ and from 6.0 to $13.3 \mathrm{~cm}$, respectively. Net radiation rarely exceeded $400 \mathrm{~W} \mathrm{~m}^{-2}$, and latent heat was generally under $200 \mathrm{~W} \mathrm{~m}^{-2}$. Simulation results matched each other very well, but net radiation and sensible heat flux were overpredicted. Goodness-of-fit measures for simulation results are shown in table 3 .

During 2 to 21 April (days 92-111) of 2003, winter wheat was in the stem extension stage. During this time, air temperature and solar radiation rose slowly but were still low. In the stem extension prophase, LAI doubled, reaching $1.8 \mathrm{~m}^{2} \mathrm{~m}^{-2}$, and latent heat increased considerably (figs. 3 and 4). In the stem extension anaphase (days 100-111), LAI was approximately 2.0 , and plant height was $25 \mathrm{~cm}$. Simulation results matched each other very well early in the stem extension prophase, but latent heat flux simulations diverged in the stem extension anaphase (particularly days 102-106 in fig. 4). This divergence was caused by differences in LAI input to the models during this period of rapidly changing LAI. Input LAI into RZ-SHAW from day 100 to day 108 was 2.2 and was updated to 3.3 on day 108, while SHAW interpolated LAI between these dates. Therefore, RZ-SHAW simulated lower $\lambda \mathrm{E}$ rates compared to SHAW due to the lower input LAI just prior to day 108 and higher $\lambda \mathrm{E}$ shortly after day 108 . Statistical comparisons for this growth stage are presented in table 3. Both models slightly overpredicted net radiation and sensible heat flux during this stage, while latent heat flux simulations were mixed (table 3). 

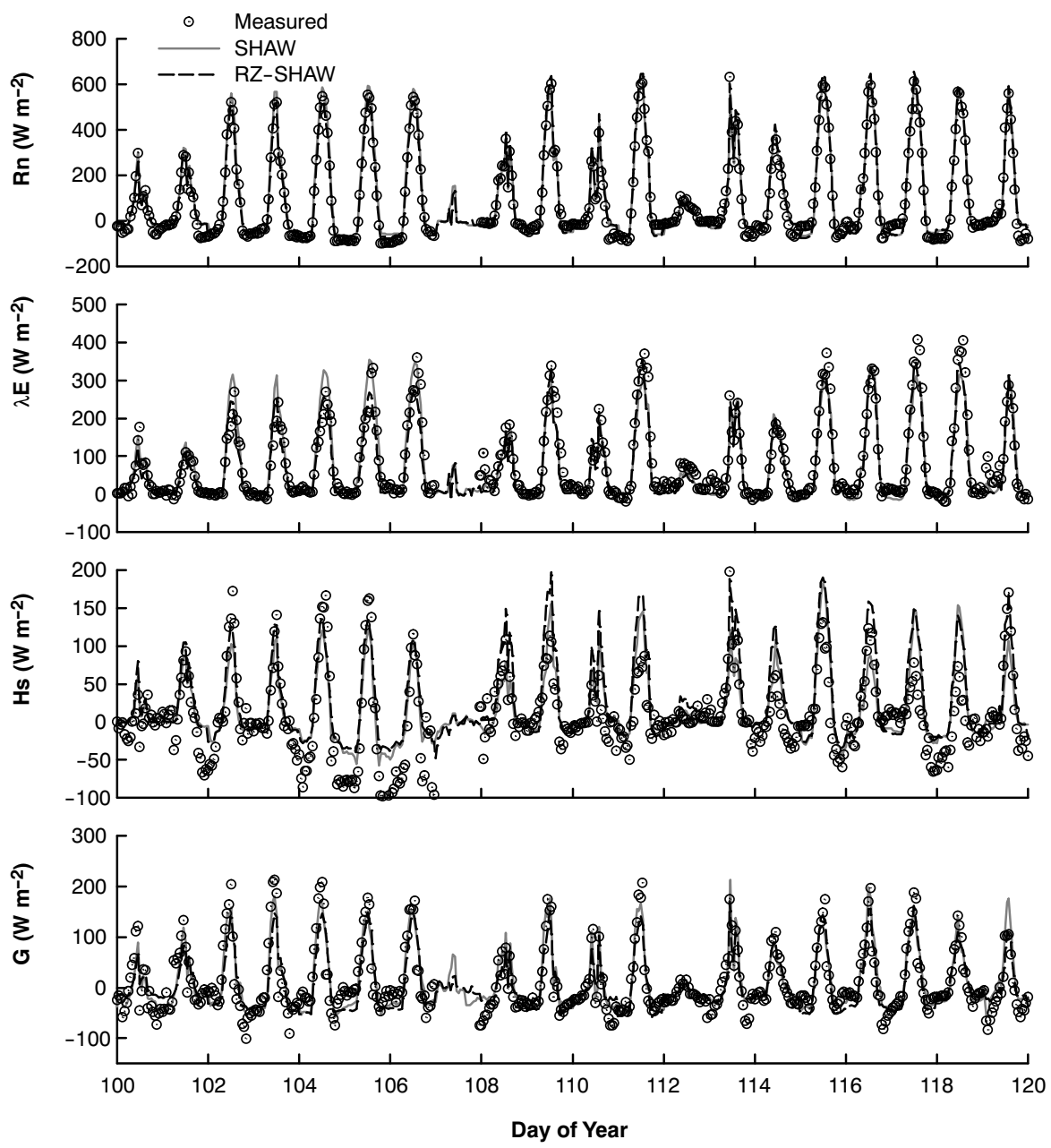

Figure 4. Measured and simulated diurnal variations of net radiation $\left(R_{n}\right)$ and latent $(\lambda E)$, sensible $\left(H_{s}\right)$, and soil heat fluxes $(G)$ using SHAW and $R Z$ SHAW for 10 to 29 April 2003 (days 100-119).

During the growth stage of heading (days 112-125), LAI was approximately 4.0 , and plant height was $65 \mathrm{~cm}$. The trend of the evapotranspiration simulations was smooth, and the simulations agreed well with each other (figs. 4 and 5). Both models underpredicted daytime latent heat flux, with a corresponding overprediction of daytime sensible heat flux. Measured nighttime sensible heat flux indicates frequent periods of significant negative (surface warming) fluxes during this growth stage, which the models did not simulate (e.g., days 118, 121, 122, and 124). These periods typically correspond with overpredicting (less negative) nighttime radiation by approximately $40 \mathrm{~W} \mathrm{~m}^{-2}$. It is unclear whether this is related to inaccurate measurement or problems in simulating net long-wave radiation. Modifications suggested by Xiao et al. (2006b) for estimating incoming long-wave radiation were tested but did not improve the simulations significantly.

Figure 5 illustrates flux simulation during the maturing growth stage (days 126-139). Due to senescence in the maturing stage, plants consisted of green transpiring leaves and yellow non-transpiring leaves. The simulated crop was divided into two types: (1) green leaves that have the capability of photosynthesis and transpiration, and (2) shriveled leaves and stems that intercept solar radiation but do not assimilate nor transpire. The green leaf area index (GLAI) was approximately 2.5 , and the yellow leaf area index (YLAI) was 1.0 in this growth period. The heights of green and shriveled plants were 71 and $50 \mathrm{~cm}$, respectively. Again, simulation results from the two models matched each other well. Simulated turbulent fluxes did not change appreciably if the effect of the shriveled plant was not considered, i.e., using GLAI for LAI input. However, when the YLAI was included in the LAI input, i.e., LAI = YLAI + GLAI, simulation results for both SHAW and RZ-SHAW did not agree as well with measured values (data not shown).

\section{RZ-SHAW Plant Growth Analysis}

RZ-SHAW with the plant growth routine enabled was used to simulate the entire 2002-2003 winter wheat season from planting through harvest (15 October through 10 June), thereby generating plant height and LAI values to be used by the energy balance routines. The plant growth parameters were optimized to give the best plant growth simulation. These parameters include the amount of biomass to obtain an LAI of 1.0 and the number of days to reach particular growth stages. However, the senescence of the crop, and therefore the effect of YLAI, could not be captured by the model simulation. Parameter values are summarized in table 4. The resulting simulation is referred to as RZ-SHAW-P, i.e., RZSHAW with the plant growth routines enabled. (Note: RZSHAW-P is not a new model, but only indicates the use of RZSHAW's plant growth simulation modules). 

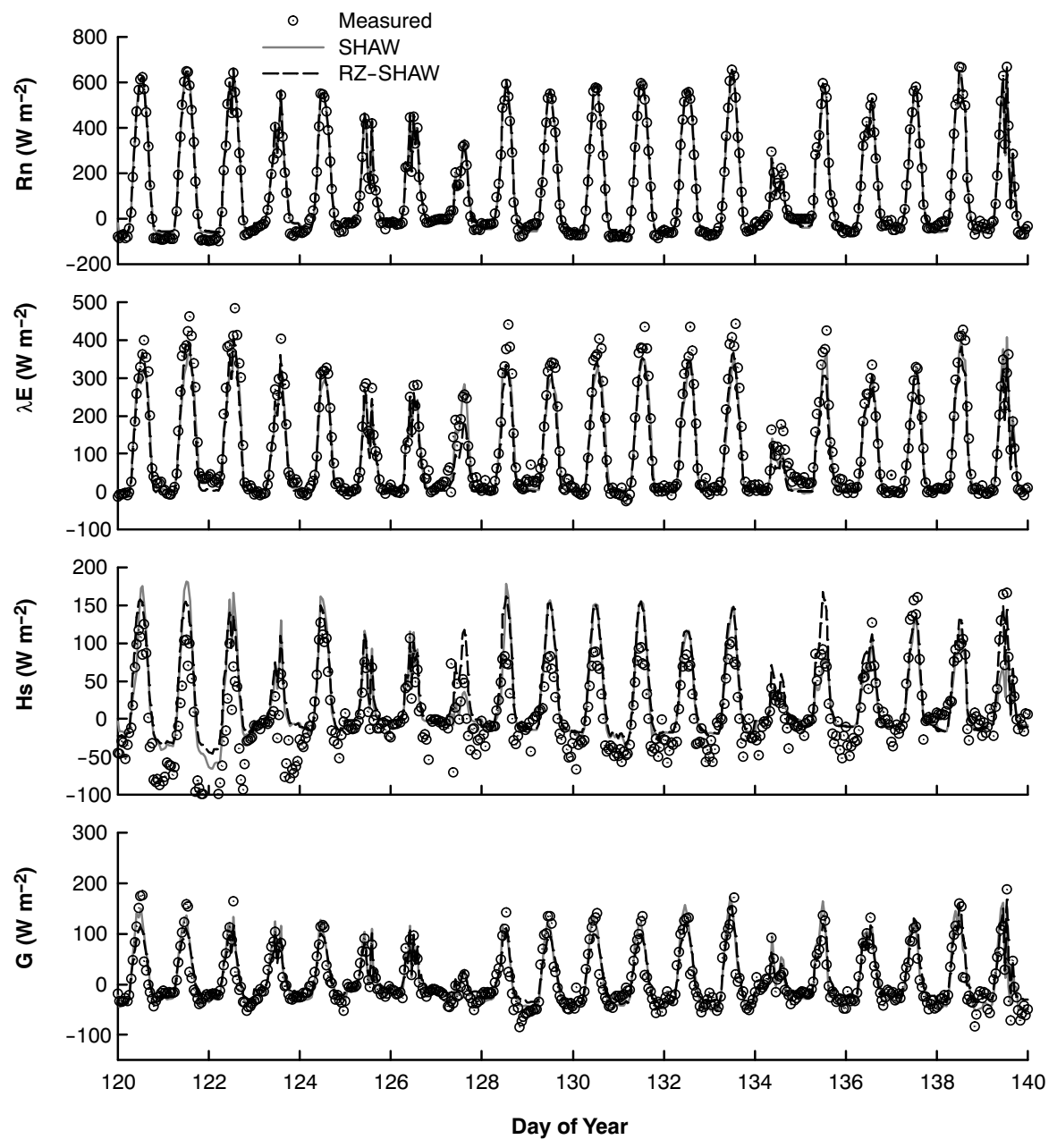

Figure 5. Measured and simulated diurnal variations of net radiation $\left(R_{n}\right)$ and latent $(\lambda E)$, sensible $\left(H_{s}\right)$, and soil heat fluxes $(G)$ using SHAW and $R Z$ SHAW for 30 April to 19 May 2003 (days 120-139).

Simulated plant heights for the RZ-SHAW-P simulation agreed very well with the measured values, as shown in figure $6 \mathrm{~b}$ from 21 March through 2 June 2003. Simulated LAI also agreed very well with measurements (fig. 6a), producing a Nash-Sutcliffe $\mathrm{R}^{2}$ of 0.88 and MBE of only 0.01 . The simulated yield (4446 $\mathrm{kg} \mathrm{ha}^{-1}$ ) was within $15 \%$ of actual yield (5250 $\mathrm{kg} \mathrm{ha}^{-1}$ ); however, simulated aboveground biomass $\left(14,536 \mathrm{~kg} \mathrm{ha}^{-1}\right)$ deviated from the measured value $\left(15,101 \mathrm{~kg} \mathrm{ha}^{-1}\right)$ by $4 \%$. Soil water contents simulated by RZ-SHAW-P are plotted in figure 2; RMSE for the $20 \mathrm{~cm}$ and $40 \mathrm{~cm}$ simulated water contents are 0.030 and $0.014 \mathrm{~m}^{3} \mathrm{~m}^{-3}$, respectively.

Net radiation and latent, sensible, and soil heat fluxes at each growing stage of wheat simulated by RZ-SHAW and

Table 4. Plant growth parameter optimization for the RZ-SHAW-P model simulation.

\begin{tabular}{lc}
\hline Parameter & Value \\
\hline Crop biomass needed for LAI $=1.0$ & $0.9 \mathrm{~g} \mathrm{~m}^{-2}$ \\
Time for plant to germinate & 2 days ${ }^{[\mathrm{a}]}$ \\
Time for plant to emerge & 7 days \\
Tia] \\
Time for plant to reach the four-leaf stage & 25 days $^{[\mathrm{a}]}$ \\
Time for plant to complete vegetative growth & 140 days $^{[\mathrm{a}]}$ \\
[a] $_{\text {Indicates minimum time for plant to complete growth } \text { stage with no }^{[\mathrm{a}}}$ \\
$\quad$ stress or winter dormancy.
\end{tabular}

RZ-SHAW-P were compared to measured values for spring 2003. The simulated and measured values are plotted for the same three time periods evaluated previously: 20 March to 8 April 8 (fig. 7), 9 to 28 April (fig. 8), and 29 April to 18 May (fig. 9).
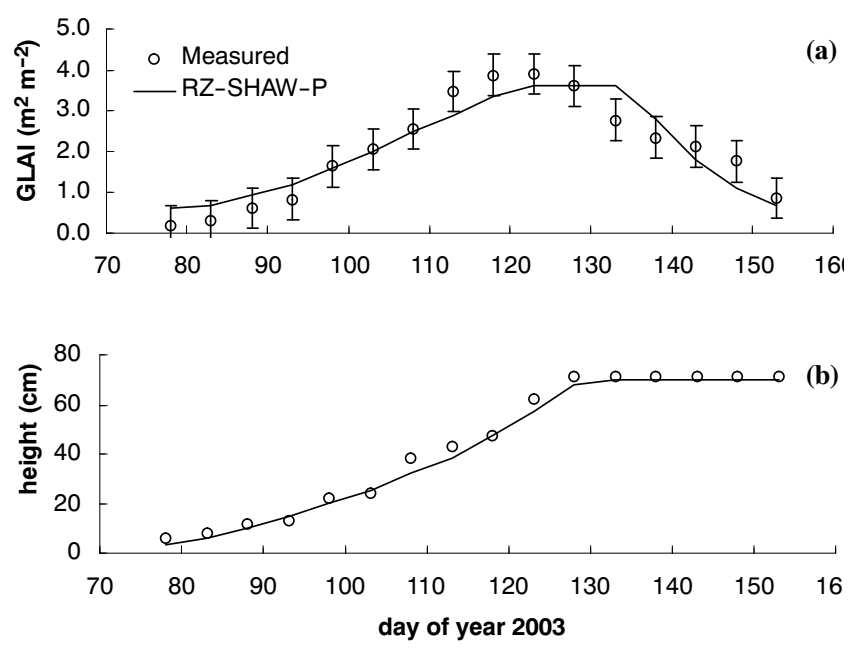

Figure 6. Measured and RZ-SHAW simulated (RZ-SHAW-P) (a) green leaf area index (GLAI) and (b) and plant height for spring growing season 2003. 


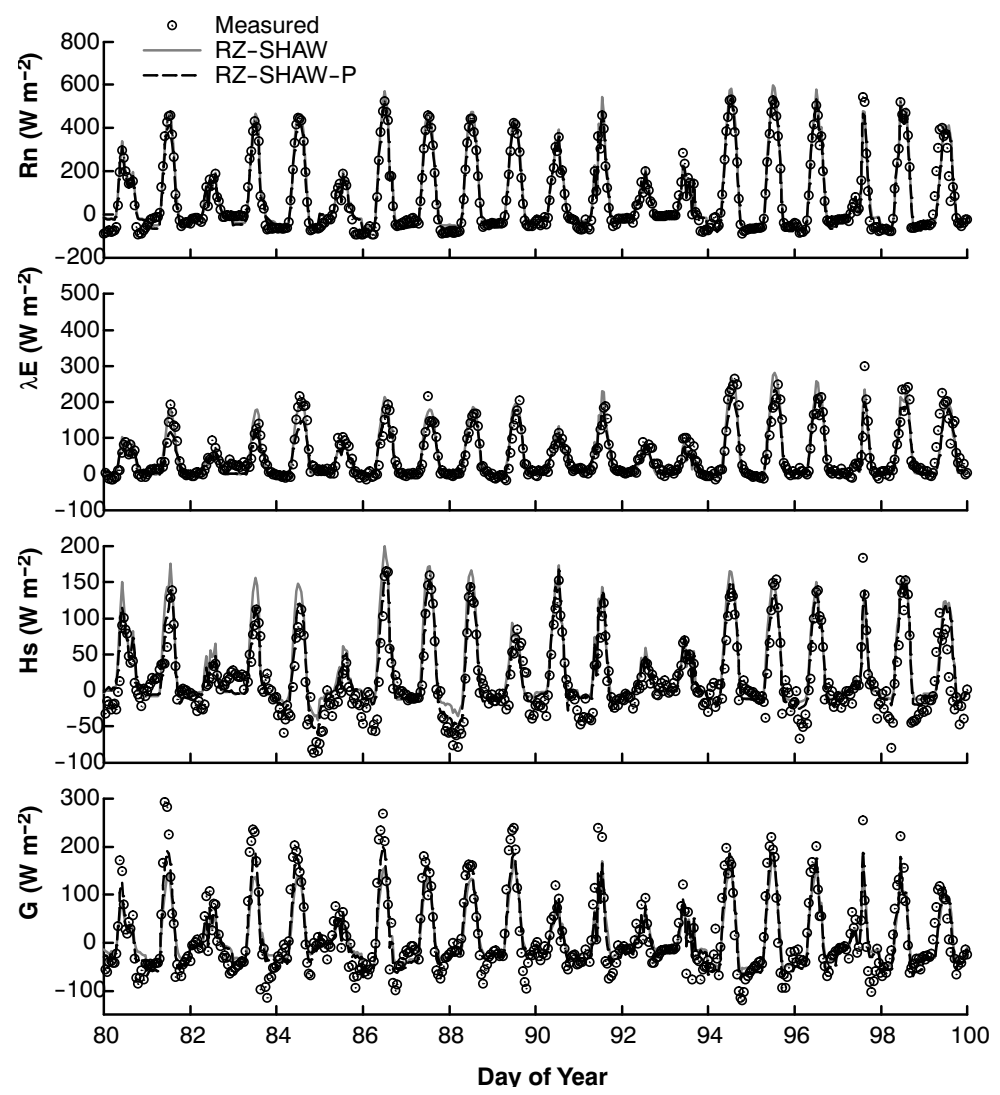

Figure 7. Measured and simulated diurnal variations of net radiation $\left(\mathbf{R}_{n}\right)$ and latent $(\lambda E)$, sensible $\left(H_{s}\right)$, and soil heat fluxes $(G)$ for RZ-SHAW-P and RZ-SHAW simulations for 21 March to 9 April 2003 (days 80-99).
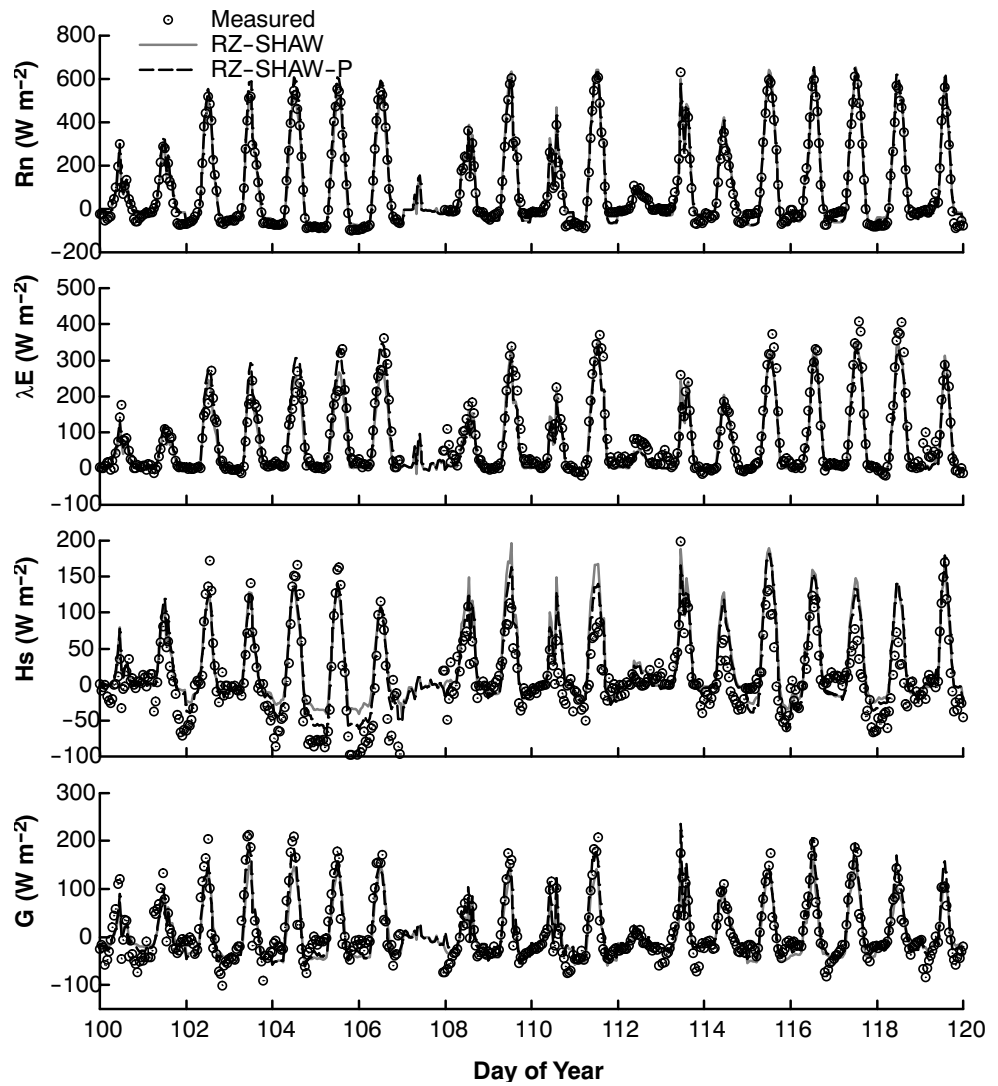

Figure 8. Measured and simulated diurnal variations of net radiation $\left(\mathbf{R}_{n}\right)$ and latent $(\lambda E)$, sensible $\left(H_{s}\right)$, and soil heat fluxes $(G)$ for $R Z-S H A W-P$ and RZ-SHAW simulations for 10 to 29 April 2003 (days 100-119). 

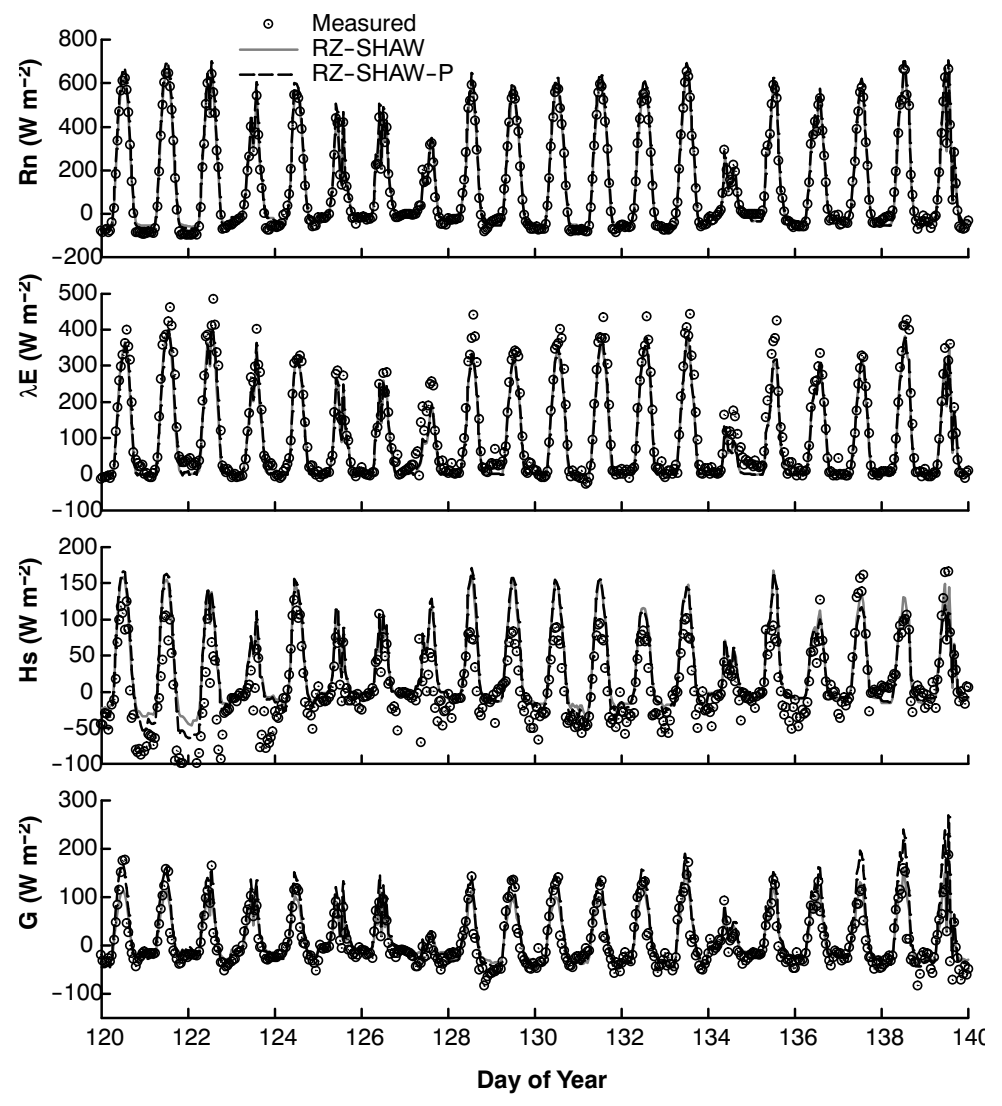

Figure 9. Measured and simulated diurnal variations of net radiation $\left(R_{n}\right)$ and latent $(\lambda E)$, sensible $\left(H_{s}\right)$, and soil heat fluxes $(G)$ for $R Z-S H A W-P$ and RZ-SHAW simulations for 30 April to 19 May 2003 (days 120-139).

During the greening stage (days 80-91; fig. 7), RZSHAW-P slightly overpredicted LAI, resulting in less solar radiation absorption by the relatively dark soil beneath the sparse canopy. This actually resulted in slightly better simulation of $\mathrm{R}_{\mathrm{n}}$ and $\mathrm{H}_{\mathrm{s}}$ by RZ-SHAW-P compared to RZ-SHAW, which overpredicted these fluxes during this growth stage (table 3). The effect on the bias error in $\mathrm{G}$ was minimal, but the variation in $\mathrm{G}$ during this period was simulated better by RZ-SHAW-P, as reflected in the reduced RMSE for G (30.6 $\mathrm{W} \mathrm{m}{ }^{-2}$ compared to $42.2 \mathrm{~W} \mathrm{~m}^{-2}$ for RZ-SHAW).

During the stem extension stage (days 92-111; figs. 7 and 8), RZ-SHAW-P simulated LAI (fig. 6) and soil moisture (fig. 2) quite well, and the energy fluxes are therefore very similar to the RZ-SHAW simulation (table 3). RZ-SHAW-P slightly overpredicted LAI (fig. 6) and overpredicted $20 \mathrm{~cm}$ soil water content (fig. 2) during the heading phase (days 112-125). By this time, the crop had reached full canopy closure, and therefore slight errors in LAI had very little effect on simulated $\lambda \mathrm{E}$. The largest difference between the RZSHAW-P and RZ-SHAW simulations during the heading phase was that RZ-SHAW-P overpredicted G more than RZSHAW (table 3); even so, RMSE for the two simulations are very similar during this period. RZ-SHAW-P overpredicted $\mathrm{R}_{\mathrm{n}}$ more than RZ-SHAW during the maturing stage, perhaps due to neglecting the effect of the senesced leaves during this stage. This had very little effect in simulated $\lambda \mathrm{E}$ and $\mathrm{H}_{\mathrm{s}}$, but translated to an overprediction of $\mathrm{G}$ as well.

Statistical performance measures for the RZ-SHAW-P simulations over the entire spring growing period (days 80-139) compared well with the MBE an RMSE values for SHAW and RZ-SHAW (table 3). The largest deviations in the
RZ-SHAW-P simulation compared to RZ-SHAW were for sensible and soil heat fluxes, which affects plant germination, residue decomposition, and soil freezing. While the results in bias error are mixed compared to the RZ-SHAW simulation, RMSE actually decreased for both $\mathrm{H}_{\mathrm{s}}$ and $\mathrm{G}$.

\section{Summary AND CONClusion}

The SHAW model has a more detailed description of radiation transmittance and water movement from soil and plants to the atmosphere than RZWQM; however, plant growth is not included. RZWQM is much more comprehensive in simulation of the soil-plant growth processes, but lacks the ability to simulate diurnal patterns in the energy balance and soil heat flux. It was shown that the hybrid RZ-SHAW model based on hourly time steps will provide a good energy balance simulation for the RZWQM.

In the first part of this study, periodic inputs of LAI and plant height were supplied to the SHAW and RZ-SHAW models. The RMSE values for simulated net radiation, latent heat, sensible heat, and soil heat were 29.7, 30.7, 29.9, and $25.9 \mathrm{~W} \mathrm{~m}^{-2}$ for SHAW and 30.6, 32.9, 34.2, and $30.6 \mathrm{~W} \mathrm{~m}^{-2}$ for RZ-SHAW, respectively, during the 60-day study, compared to measured values. Close correspondence between the SHAW and RZ-SHAW simulation results suggests a successful implementation of the SHAW energy balance routines into the RZ-SHAW model.

The second part of this study was performed using the RZSHAW plant growth simulation (RZ-SHAW-P) that generates LAI, plant height, and biomass, as well as surface energy bal- 
ance and soil water content. Plant growth and soil water content were simulated well by the RZ-SHAW-P simulation. Therefore, the RZ-SHAW-P simulation results for net radiation and latent, sensible, and soil heat fluxes compared very closely with the RZ-SHAW results. The largest difference in the RZ-SHAW-P simulated energy balance compared to RZ-SHAW was for the sensible and soil heat fluxes, which were both fortuitously simulated better by RZ-SHAW-P (RMSE of 30.2 and $27.6 \mathrm{~W} \mathrm{~m}^{-2}$ for sensible and soil heat fluxes, respectively).

Overall, the study results demonstrated a successful coupling of RZWQM and SHAW in terms of canopy energy balance simulation. When plant growth was enabled and effectively simulated, RZ-SHAW simulations were comparable to the SHAW model. The addition of a detailed surface energy balance with RZWQM allows feedback between the environmental conditions and plant growth. The ability to accurately simulate the surface energy balance can enhance land management, e.g., irrigation can influence latent and sensible heat fluxes. Furthermore, RZ-SHAW has accurately simulated residue management systems, as residue also affects the thermal dynamics of evaporative surfaces (Kozak et al., 2007). Emergence and development of crops, their pests, and various soil organisms are altered by heat and water movement near the soil-atmosphere interface. RZ-SHAW can be offered as a new model with the comprehensive land management options of RZWQM and the additional capability to simulate diurnal changes in energy balance, which is needed for simulating canopy, surface residue, and snow effects on soil temperature and water.

\section{ACKNOWLedgement}

This work is supported by National Natural Science Foundation of China (Grant No. 40328001).

\section{REFERENCES}

Ahuja, L. R., and L. Ma. 2002a. Parameterization of agricultural system models: Current issues and techniques. In Agricultural System Models in Field Research and Technology Transfer, 273-316. L. R. Ahuja, L. Ma, and T. A. Howell, eds. Boca Raton, Fla.: CRC Press.

Ahuja, L. R., and L. Ma. 2002b. Computer models to guide soil water management for plants. In Encyclopedia of Soil Science, 218-222. R. Lal, ed. New York, N.Y.: Marcel Dekker.

Ahuja, L. R., K. W. Rojas, J. D. Hanson, M. J. Shaffer, and L. Ma, eds. 2000a. Root Zone Water Quality Model. Highland Ranch, Colo.: Water Resources Publications.

Ahuja, L. R., K. E. Johnsen, and K. W. Rojas. 2000b. Water and chemical transport in soil matrix and macropores. In Root Zone Water Quality Model, 13-50. L. R. Ahuja, K. W. Rojas, J. D. Hanson, M. J. Shaffer, and L. Ma, eds. Highland Ranch, Colo.: Water Resources Publications.

Aiken, R. M., G. N. Flerchinger, H. J. Farahani, and K. A. Johnsen. 1997. Energy balance simulation for surface soil and residue temperatures with incomplete cover. Agron. J. 89(3): 404-415.

Farahani, H. J., W. C. Baushch, R. M. Aiken, and L. R. Ahuja. 1996. Evapotranspiration in system-wide agricultural models. In Proc. Intl. Conf.: Evapotranspiration and Irrigation Scheduling, 673-678. St. Joseph, Mich.: ASAE.

Flerchinger, G. N., and K. E. Saxton. 1989a. Simultaneous heat and water model of a freezing snow-residue-soil system: I. Theory and development. Trans. ASAE 32(3): 565-571.

Flerchinger, G. N., and K. E. Saxton. 1989b. Simultaneous heat and water model of a freezing snow-residue-soil system: II. Field verification. Trans ASAE 32(3): 573-578.
Flerchinger, G. N., and F. B. Pierson. 1991. Modeling plant canopy effects on variability of soil temperature and water. Agric. Forest Meteorol. 56(3-4): 227-246.

Flerchinger, G. N., K. R. Cooley, and Y. Deng. 1994. Impacts of spatially and temporally varying snowmelt on subsurface flow in a mountainous watershed: 1 . Snowmelt Simulation. Hydrol. Sci. J. 39(5): 507-520.

Flerchinger, G. N., J. M. Baker, and E. J. A. Spaans. 1996a. A test of the radiative energy balance of the SHAW model for snow cover. Hydrol. Proc. 10(10): 1359-1367.

Flerchinger, G. N., C. L. Hanson, and J. R. Wight. 1996b. Modeling of evapotranspiration and surface energy budgets across a watershed. Water Resour. Res. 32(8): 2539-2548.

Flerchinger, G. N., W. P. Kustas, and M. A. Weltz. 1998. Simulating surface energy fluxes and radiometric surface temperatures for two arid vegetation communities using the SHAW model. $J$. Appl. Meteor. 37(5): 449-460.

Flerchinger, G. N., R. M. Aiken, K. W. Rojas, and L. R. Ahuja, 2000. Development of the Root Zone Water Quality Model (RZWQM) for over-winter conditions. Trans ASAE 43(1): 59-68.

Flerchinger, G. N., T. J. Sauer, and R. M. Aiken. 2002. Effects of crop residue cover and architecture on heat and water transfer at the soil surface. Geoderma 116(1-2): 217-233.

Hanson, J. D. 2000. Generic crop production. In Root Zone Water Quality Model, 81-118. L. R. Ahuja, K. W. Rojas, J. D. Hanson, M. J. Shaffer, and L. Ma, eds. Highland Ranch, Colo.: Water Resources Publications.

Hymer, D. C., M. S. Moran, and T. O. Keefer. 2000. Soil water evaluation using a hydrologic model and calibrated sensor network. SSSA J. 64(1): 319-326.

Kennedy, I., and B. Sharratt. 1998. Model comparisons to simulate frost depth. Soil Sci. 163(8): 636-645.

Kozak, J. A., R. M. Aiken, G. N. Flerchinger, D. Nielsen, L. Ma, and L. R. Ahuja. 2007. Quantifying residue architecture effects on soil heat flux. Soil Tillage Res. (in press).

Lee, X. H., and Q. Yu. 2004. Micrometeorological fluxes under the influence of regional and local advection: A revisit. Agric. Forest Meteorol. 122(1-2): 111-124.

Link, T. E., G. N. Flerchinger, M. H. Unsworth, and D. Marks. 2004. Simulation of water and energy fluxes in an old growth seasonal temperate rainforest using the Simultaneous Heat and Water (SHAW) model. J. Hydrometeorol. 5(3): 443-457.

Ma, L., L. R. Ahuja, J. C. Ascough II, M. J. Shaffer, K. W. Rojas, R. W. Malone, and M. R. Cameira. 2000. Integrating system modeling with field research in agriculture: Applications of the Root Zone Water Quality Model (RZWQM). Advances in Agron. 71: 233-292.

Nash, J. E., and J. V. Sutcliffe. 1970. River flow forecasting through conceptual models: Part I. A discussion of principles. J. Hydrol. 10(3): 282-290.

Twine, T. E., W. P. Kustas, J. M. Norman, D. R. Cook, P. R. Houser, T. P. Meyers, J. H. Prueger, P. J. Starks, and M. L. Wesely. 2000. Correcting eddy-covariance flux underestimates over a grassland. Agric. Forest Meteor. 103(3): 279-300.

Wilson K, A Goldstein, E. Falge, M. Aubinet, D. Baldocchi, P. Berbigier, C. Bernhofer, R. Ceulemans, H. Dolman, C. Field, A. Grelle, A. Ibrom, B. Law, A. Kowalski, T. Meyers, J. Moncrieff, R. Monson, W. Oechel, J. Tenhunen, R. Valentini, and S. Verma. 2002. Energy balance closure at FLUXNET sites. Agric. Forest Meteorol. 113(1): 223-243.

Xiao, W., G. N. Flerchinger, Q. Yu, and Y. Zheng. 2006a. Evaluation of SHAW model in simulating the components of net all-wave radiation. Trans. ASABE 49(5): 1351-1360.

Xiao, W., Q. Yu, G. N. Flerchinger, and Y. F. Zheng. 2006b. Evaluation of SHAW model in simulating energy balance, leaf temperature, and microclimate within a maize canopy. Agron. J. 98(3): 722-729. 